\title{
PRODUTIVIDADE DE PLANTAS FORRAGEIRAS EM FUNÇÃO DE MANEJO DO SOLO
}

\section{EDNEY L. DA VITÓRIA ${ }^{1}$, HAROLDO C. FERNANDES ${ }^{2}$, MAURI M. TEIXEIRA ${ }^{3}$, PAULO R. CECON ${ }^{4}$}

\begin{abstract}
RESUMO: O manejo do solo inadequado, aliado a uma baixa fertilidade do solo, constitui um dos principais fatores limitantes da produção pecuária nas regiões tropicais. Objetivou-se neste trabalho avaliar a produtividade de duas espécies de plantas forrageiras submetidas a três sistemas de preparo do solo, obtendo as correlações entre produtividade de matéria seca e índice de área foliar, em função do período de crescimento. O experimento foi instalado em esquema de parcela subsubdividida, no delineamento em blocos casualizados, com quatro repetições. Somente o manejo do solo, o período e a interação entre o período e a forrageira apresentaram diferença considerada significativa $(\mathrm{p}<0,05)$ em relação à produção de matéria seca e índice de área foliar. Porém, estatisticamente, o manejo do solo não apresentou diferença significativa na interação com o tipo de forrageira. Os sistemas de manejo do solo utilizados influenciam na produção de matéria seca, independentemente da forrageira, sendo que o preparo convencional apresentou melhores resultados.
\end{abstract}

PALAVRAS-CHAVE: preparo do solo, forragicultura, propriedades físicas do solo.

\section{PRODUCTIVITY OF FORAGE PLANTS SOIL MANAGEMENT}

\begin{abstract}
The handling of the ground inadequate, ally to one low fertility of the ground, constitutes one of the main limitantes factors of the cattle production in the tropical regions. The objective was influences to study it of system of handling of the ground on the productivity of forrageiras in terms of productivity of dry substance. The experiment was installed in project of parcel sub-subdivided in the delineation block-type with four repetitions. Only the handling of the ground, the period and the interaction between period and the forrageira had presented considered difference significant $(\mathrm{p}<0,05)$ in relation to the production of dry substance and index of foliar area. However, statistical the handling of the ground did not present significant difference in the interaction with the type of forrageira. The systems of used handling of the ground influence in the production of dry, independent substance of the forrageira, being that the conventional preparation presented better resulted.
\end{abstract}

KEYWORDS: soil management, crop forage, soil physical attributes.

\section{INTRODUÇÃO}

As espécies forrageiras representam as plantas de interesse econômico mais cultivadas no mundo. Contudo, o pequeno número de espécies forrageiras com valor nutricional satisfatório, aliado à baixa fertilidade e manejo inadequado do solo, constitui um dos principais fatores limitantes da produção pecuária nas regiões tropicais.

A intensificação da mecanização é usada constantemente com intuito de melhorar as condições de implantação e desenvolvimento de plantas forrageiras. Entretanto, muitas vezes, a produtividade é comprometida pelo excesso ou pela inadequação de práticas às quais o solo é

\footnotetext{
${ }^{1}$ Eng $^{\circ}$ Agrícola, Prof. Dr., Depto. de Ciências Agrárias e Biológicas, Universidade Federal do Espirito Santo, São Mateus - ES, Fone: (27) 3312-1986, edney.vitoria@ufes.br.

${ }^{2}$ Eng ${ }^{\circ}$ Agrícola, Prof. Dr., Depto. de Engenharia Agrícola, Universidade Federal de Viçosa, Viçosa - MG, haroldo@ufv.br.

${ }^{3}$ Eng $^{\circ}$ Agrônomo, Prof. Dr., Depto. de Engenharia Agrícola, Universidade Federal de Viçosa, Viçosa - MG, mauri@ufv.br.

${ }^{4}$ Eng $^{\circ}$ Agrônomo, Prof. Dr., Depto. de Estatística, Universidade Federal de Viçosa, Viçosa-MG, cecon@ ufv.br

Recebido pelo Conselho Editorial em: 14-2-2011

Aprovado pelo Conselho Editorial em: 10-5-2014
}

Eng. Agríc., Jaboticabal, v.34, n.5, p. 955-962, set./out. 2014 
submetido, desde seu preparo até a colheita da cultura que nele se estabeleceu. Embora o objetivo do manejo do solo seja alterar algumas de suas propriedades físicas, conferindo-lhes condições que favoreçam o crescimento e o desenvolvimento das plantas, via de regra, tem proporcionado degradação em função de manejos de solo inadequados.

O sistema de manejo do solo com grade aradora tem sido o mais usado na implantação de forrageiras. Normalmente, a grade trabalha o solo a pouca profundidade e apresenta alto rendimento de campo, porém o uso contínuo desse implemento pode levar à formação de camadas compactadas, chamadas "pé-de-grade" (CORTEZ et al., 2011).

O plantio direto pode ser uma alternativa ao sistema convencional de preparo do solo e contribuir para a sustentabilidade de sistemas agrícolas intensivos, por manter o solo coberto por restos culturais ou por plantas vivas o ano inteiro, minimizando os efeitos da erosão (COSTA et al., 2009).

No sistema plantio direto em geral, os solos apresentam, na camada superficial, após três a quatro anos, maiores valores de densidade e microporosidade, e menores valores de macroporosidade e porosidade total, quando comparados com o preparo convencional, decorrente, sobretudo, do arranjamento natural do solo, quando não é mobilizado, e da pressão provocada pelo trânsito de máquinas e implementos agrícolas, em particular quando realizado em solos argilosos e com teores elevados de umidade (CASTRO et al., 2009).

Verifica-se que, para algumas culturas, o preparo mínimo do solo propicia maiores produções em comparação com o convencional. No entanto, são poucos os resultados de avaliações dos efeitos dos sistemas de manejo do solo (KAMIMURA et al., 2009).

Analisando três sistemas de manejo de solo em termos de produtividade da Panicum maximum, VALÊNCIA et al. (2008) verificaram que o plantio direto proporcionou rendimento $17 \%$ superior em relação ao manejo que utilizou somente as grades pesada e leve, notando-se que os manejos conservacionistas que utilizaram o escarificador e o plantio direto, tiveram sua produtividade aumentada com o decorrer do tempo.

O sistema de manejo do solo não influenciou na produtividade da cana-de-açúcar de forma significativa, porém o manejo do solo com implementos que permitem manejos mais profundos do solo propiciou as maiores produções de cana-de-açúcar (SERAFIM et al., 2011).

Neste contexto, o objetivo deste trabalho é avaliar a produtividade e o índice de área foliar de duas espécies de plantas forrageiras submetidas a três sistemas de preparo do solo, obtendo as correlações entre produtividade de matéria seca e índice de área foliar, em função do período de crescimento.

\section{MATERIAL E MÉTODOS}

Este trabalho foi realizado na área experimental do Instituto Federal de Ensino Superior, Câmpus de Santa Teresa, localizada no município de Santa Teresa, região Serrana do Estado do Espírito Santo, situado entre as coordenadas 1949'09' de latitude sul e 4040'17' 'de longitude oeste de Greenwich, e altitude média de $675 \mathrm{~m}$. O clima da região é temperado úmido com inverno seco e verão quente, Cwa. A média de temperatura fica entre 16 e $18^{\circ} \mathrm{C}$. O solo é classificado como Latossolo Amarelo eutrófico, textura arenosa, com $300 \mathrm{~g} \mathrm{~kg}^{-1}$ de argila, $70 \mathrm{~g} \mathrm{~kg}^{-1}$ de silte e $630 \mathrm{~g} \mathrm{~kg}^{-}$ ${ }^{1}$ de areia, conforme COLET (2009).

A área experimental foi cultivada nos cinco anos anteriores à implantação do experimento, em um sistema de preparo conservacionista, rotação de cultura e cultivo mínimo do solo, com as culturas de sorgo (Sorghum bicolor), Colonião (Panicum maximum) e Tifton (Cynodon spp). As adubações para as culturas foram realizadas conforme recomendações técnicas baseadas em análises de solo. 
Para a caracterização da área experimental, os atributos físicos do solo estudados foram a densidade do solo (Ds), a porosidade total (Pt), o volume de macroporos (Mac), o volume de microporos (Mic) e a resistência do solo à penetração $(\mathrm{Rp})$, além da umidade gravimétrica do solo (Ug), e todos foram determinados utilizando o método da EMBRAPA (1997).

O experimento foi instalado em esquema de parcela subsubdividida, sendo as parcelas constituídas por três sistemas de manejo do solo (preparo convencional, cultivo mínimo e plantio direto); as subparcelas constituídas por duas forrageiras (Brachiaria brizantha e mombaça); e as subsubparcelas por cinco períodos de avaliação de produtividade $(30 ; 45 ; 60 ; 75$ e 90 dias após o plantio). O experimento foi instalado no delineamento em blocos casualizados, com quatro repetições. As unidades experimentais tinham 6 metros de largura e 20 metros de comprimento, espaçadas 3 metros entre si.

O manejo de solo convencional (PC) foi feito com uma passada do arado de discos com o objetivo de revolver a leiva do solo e incorporar o resto de cultura e palhada dessecada, depois duas passadas com a grade destorroadora para destorroar e nivelar o solo ao ponto de receber as sementes das forrageiras.

Para o cultivo mínimo (CM), utilizou-se de uma passada do cultivador com hastes espaçadas de $0,20 \mathrm{~m}$, o mesmo espaçamento utilizado no plantio das forrageiras com intuito de que as sementes fossem depositadas apenas no local onde o solo foi trabalhado.

No plantio direto (PD), as sementes das forrageiras foram depositadas diretamente sobre a palhada dessecada, utilizando-se de uma semeadora-adubadora marca Semeato, plantio direto, modelo SHMA/11, 11 linhas, capacidade do depósito de sementes de $38 \mathrm{~L}$, capacidade do depósito de fertilizante de $366 \mathrm{~L}$. A semeadora-adubadora foi regulada para um espaçamento entre linhas de 0,20 $\mathrm{m}$, e as sementes foram depositadas no solo em uma profundidade média de $0,02 \mathrm{~m}$, tanto para Brachiaria brizantha quanto para a mombaça. Foram semeados $12,0 \mathrm{~kg} \mathrm{ha}^{-1}$ de sementes das duas forrageiras, independentemente do manejo de solo.

Para avaliar a produtividade, foi utilizado o método da matéria seca total (MS) em cada um dos períodos após o plantio, ou seja, 30; 45; 60; 75 e 90 dias. Para a determinação da produção de matéria seca, a forrageira foi cortada, em média, a $0,10 \mathrm{~m}$ do solo. $\mathrm{O}$ corte foi feito em pontos aleatórios da unidade experimental, utilizando um gabarito de $1 \mathrm{~m}^{2}$. O material coletado foi colocado em saco de papel identificado, pesado e levado à estufa com ventilação forçada, às temperaturas entre 60 e $65^{\circ} \mathrm{C}$, para determinação de sua matéria seca e estimativa da produção de matéria seca total.

O índice de área foliar foi determinado indiretamente com aparelho analisador (ceptômetro) de dossel AccuPAR, modelo LP-80. As medições foram realizadas a partir de uma leitura de referência sobre o dossel forrageiro e uma das leituras feitas abaixo do dossel (no nível do solo). As medições foram realizadas sempre ao amanhecer, evitando uma superestimativa recorrente da elevada radiação transmitida pelas folhas, quando a luz incide diretamente. Em cada unidade experimental, foram realizadas 10 leituras acima e 10 leituras abaixo do dossel.

Os efeitos dos sistemas de manejo do solo sobre a produtividade e o índice de área foliar das forrageiras foram interpretados pela análise de variância, segundo o delineamento de blocos casualizados. A diferença entre médias dos tratamentos foi avaliada pelo teste de Tukey, considerando uma significância de 5\%. Com finalidade de ajustar as curvas de produtividade e o índice de área foliar nos diferentes períodos avaliados, foi realizada a análise de regressão. Os modelos foram escolhidos com base na significância dos coeficientes de regressão e do coeficiente de determinação, utilizando o Statistical Analysis System (SAS INSTITUTE, 2002), considerando um nível de significância igual a 5\%. 


\section{RESULTADOS E DISCUSSÃO}

Na Tabela 1, são apresentadas médias das propriedades físicas da área experimental. A maior porcentagem de teor de água foi observada na faixa de 0,15 a $0,30 \mathrm{~m}$, enquanto o maior valor de densidade foi observado na faixa de 0 a $0,15 \mathrm{~m}$ de profundidade. A resistência do solo à penetração e à profundidade é diretamente proporcional, sendo que o valor máximo obtido foi de 2,44 $\mathrm{MPa}$.

TABELA 1. Teor de água no solo (UG), densidade do solo (Ds), porosidade total (Pt), macroporosidade (Mac) e microporosidade (Mic). Média \pm desvio-padrão. Soil water content, bulk density, total porosity, macroporosity and microporosity.

\begin{tabular}{lccccc}
\hline \multicolumn{1}{c}{ Faixa de profundidade $(\mathrm{m})$} & $\mathrm{Ds}\left(\mathrm{kg} \mathrm{dm}^{-3}\right)$ & $\mathrm{Pt}\left(\mathrm{m}^{3} \mathrm{~m}^{-3}\right)$ & $\mathrm{Ug}\left(\mathrm{kg} \mathrm{kg}^{-1}\right)$ & $\mathrm{Mac}\left(\mathrm{m}^{3} \mathrm{~m}^{-3}\right)$ & $\mathrm{Mic}\left(\mathrm{m}^{3} \mathrm{~m}^{-3}\right)$ \\
\hline 0 a 0,15 & $1,40 \pm 0,079$ & $0,371 \pm 0,073$ & $0,200 \pm 0,008$ & $0,093 \pm 0,018$ & $0,278 \pm 0,055$ \\
0,15 a 0,30 & $1,55 \pm 0,081$ & $0,294 \pm 0,016$ & $0,230 \pm 0,015$ & $0,073 \pm 0,004$ & $0,278 \pm 0,055$ \\
\hline
\end{tabular}

O resumo da análise de variância da matéria seca (MS) é apresentado na Tabela 2.

TABELA 2. Resumo da análise de variância da matéria seca e índice de área foliar para os fatores analisados e as diferentes interações. Summary of analysis of variance of dry matter and leaf area index for the analyzed factors and different interactions.

\begin{tabular}{llcc}
\hline \multirow{2}{*}{ Fonte de variação } & Graus de liberdade & MS & IAF \\
\cline { 3 - 4 } & & Quadrado médio \\
\hline
\end{tabular}

$\begin{array}{llll}\text { Bloco } & 3 & 58.959,3^{*} & 0,22^{*} \\ \text { Preparo (P) } & 2 & 93.036,1^{*} & 1,79^{*} \\ \text { Erro A } & 6 & 12.887,3 & 0,03 \\ \text { Forrageira (F) } & 1 & 8.217 .620,0^{\mathrm{ns}} & 6,12^{\mathrm{ns}} \\ \text { P x F } & 2 & 135,4^{\mathrm{ns}} & 0,05^{\mathrm{ns}} \\ \text { Erro B } & 9 & 4.806,9 & 0,046 \\ \text { Período (PER) } & 4 & 0,00^{*} & 90,69^{*} \\ \text { PER x P } & 8 & 3.440,99^{\mathrm{ns}} & 0,052^{\mathrm{ns}} \\ \text { PER x F } & 4 & 1.009572,0^{*} & 0,33^{*} \\ \text { PER X P X F } & 8 & 3.619,0^{\mathrm{ns}} & 0,039^{\mathrm{ns}} \\ \text { Resíduo } & 120 & 8635,8 & 0,043 \\ \text { CV }(\%) & & 3,54 & 5,64\end{array}$

$\begin{array}{lll}\text { Sistema de manejo }(\mathbf{P}) & & \\ \text { Preparo convencional } & 2.671,9 \mathrm{a} & 3,87 \mathrm{a} \\ \text { Cultivo mínimo } & 2.609,6 \mathrm{~b} & 3,69 \mathrm{~b} \\ \text { Plantio direto } & 2.598,6 \mathrm{~b} & 3,52 \mathrm{c}\end{array}$

Em cada coluna, para cada fator, médias seguidas de mesmas letras minúsculas não diferem entre si, pelo teste de Tukey, a 5\% de probabilidade. ns: não significativo $(\mathrm{p}>0,05)$;

$*$ significativo $(\mathrm{p} \leq 0,05)$.

Nos resultados apresentados na Tabela 2, verifica-se que somente o manejo do solo, o período e a interação entre período e a forrageira apresentaram diferença considerada significativa $(\mathrm{p}<0,05)$ em relação à produção de matéria seca e o índice de área foliar. Porém, estatisticamente, o manejo do solo não apresentou diferença significativa $(\mathrm{p}>0,05)$ na interação com espécie forrageira. $\mathrm{O}$ fato de não ter ocorrido interação significativa entre os sistemas de manejo do solo, 
período e forrageira na resposta de matéria seca e índice de área foliar pode ser explicado pelo manejo adequado do solo na área experimental, nos períodos anteriores à implantação do experimento. ANDRIGUETTI (2009) trabalhou com diferentes níveis de potássio e manejos do solo. Este autor não obteve diferenças significativas $(\mathrm{p}>0,05)$ na produtividade do milho forrageiro, em função do manejo do solo e do espaçamento entre linhas de plantio.

VITÓRIA et al. (2011), em estudo sobre o crescimento vegetativo da capim-mombaça submetido a diferentes manejos do solo, não encontraram diferenças significativas $(\mathrm{p}>0,05)$ no acúmulo de matéria seca, na altura de corte e no índice de área foliar. CRUZ et al. (2009) estudaram o consórcio de milho com Brachiaria brizantha e concluíram que a semeadura direta e o cultivo mínimo não proporcionaram diferenças significativas entre si, contudo apresentaram resultados inferiores ao do sistema convencional. PARIZ et al. (2011) concluíram que o acúmulo de matéria seca e o índice de área foliar em forrageiras dependem da adubação, da fertilidade do solo, da disponibilidade de água e, em menor grau, do sistema de manejo do solo.

Os resultados médios de produção de matéria seca e de índice de área foliar das forrageiras submetidas ao preparo convencional foram significativamente maiores do que os encontrados para o cultivo mínimo e para o plantio direto, o que pode ser explicado pelo fato da quebra da camada compactada na superfície, propiciando o melhor contato das sementes com o solo. Conclusão semelhante a essa foi apresentada por VITÓRIA et al. (2011), que constataram a indução de maiores produtividades sob preparo convencional, nos primeiros anos de produção. A produção de matéria seca e o índice de área foliar maiores, registrados no preparo convencional e no cultivo mínimo, quando comparados ao plantio direto, também podem estar relacionados à maior mineralização da matéria orgânica nos primeiros manejos, isto pela mobilização do solo, o que gera maior nitrogênio disponível para as culturas. O rendimento menor das forrageiras sob plantio direto pode ser atribuído à formação de camadas compactadas induzidas por esse sistema de manejo, principalmente próximo à superfície do solo, fato observado por SPERA et al. (2009).

A matéria seca e o índice de área foliar apresentaram diferenças significativas em função do período da avaliação e da forrageira, embora o sistema de manejo do solo não tenha manifestado diferenças quando sob efeito da interação com a forrageira. Observou-se uma tendência do preparo convencional proporcionar maiores produtividades tanto para Brachiaria brizantha como para om capim-mombaça. A Tabela 3 apresenta os resultados de produção de matéria seca e de índice de área foliar em função do período pós-plantio. Trinta dias após a semeadura, não se observou diferença na produção de matéria seca, entre a Brachiaria brizantha e o capim-mombaça, o que pode ser explicado pelo fato de o sistema radicular das forrageiras ser semelhante nos primeiros 30 dias. Nos demais períodos, a produção de matéria seca do capim-mombaça foi significativamente superior à da Brachiaria brizantha. Em relação ao índice de área foliar, não se observou diferença significativa $(\mathrm{p}>0,05)$ entre as forrageiras, porém a diferença é significativa quando comparada por período.

TABELA 3. Matéria seca em função do período após semeadura e forrageira. Dry matter as a function of time after seeding and forage.

\begin{tabular}{clrrrrr}
\hline \multirow{2}{*}{ Parâmetro avaliado } & \multirow{2}{*}{ Forrageira } & \multicolumn{5}{c}{ Período após a semeadura (dias) } \\
\cline { 3 - 7 } & & 30 & 45 & 60 & 75 & 90 \\
\hline \multirow{3}{*}{ Matéria seca $\left(\mathrm{kg} \mathrm{ha}^{-1}\right)$} & $\begin{array}{l}\text { Brachiaria } \\
\text { brizantha }\end{array}$ & $605,6 \mathrm{aA}$ & $915,2 \mathrm{aB}$ & $1736,1 \mathrm{aC}$ & $3910,6 \mathrm{aD}$ & $4897,1 \mathrm{aE}$ \\
& Mombaça & $652,8 \mathrm{aA}$ & $1111,7 \mathrm{bB}$ & $2079,1 \mathrm{bC}$ & $4717,6 \mathrm{bD}$ & $5640,1 \mathrm{bE}$ \\
& & & & & & \\
Índice de área foliar & $\begin{array}{l}\text { Brachiaria } \\
\text { brizantha }\end{array}$ & $1,31 \mathrm{aA}$ & $2,64 \mathrm{aB}$ & $3,74 \mathrm{aC}$ & $4,78 \mathrm{aD}$ & $5,01 \mathrm{aE}$ \\
& Mombaça & $1,41 \mathrm{aA}$ & $3,25 \mathrm{aB}$ & $4,20 \mathrm{aC}$ & $5,15 \mathrm{aD}$ & $5,39 \mathrm{aE}$ \\
\hline
\end{tabular}

Médias seguidas pela mesma letra, minúscula na coluna e mesma letra maiúscula na linha, não apresentam diferença significativa entre si, considerando um nível de $5 \%$ de probabilidade, pelo teste de Tukey. 
A análise de regressão permitiu a obtenção do modelo explanatório "raiz quadrada" que demonstra a tendência do acúmulo de matéria seca durante o período do experimento (Figura 1).

As taxas de acúmulo de matéria seca obtidas superaram as obtidas por MILLER (2002), de 7,0; 5,4 e 1,1 kg ha ${ }^{-1} \mathrm{dia}^{-1}$ para os capins Brachiaria brizantha brizantha, Andropogon gayanus e Paspalum notatum, respectivamente. Tal diferença pode ser explicada pela época de plantio e pela disponibilidade hídrica diferentes entre os resultados encontrados nos experimentos.

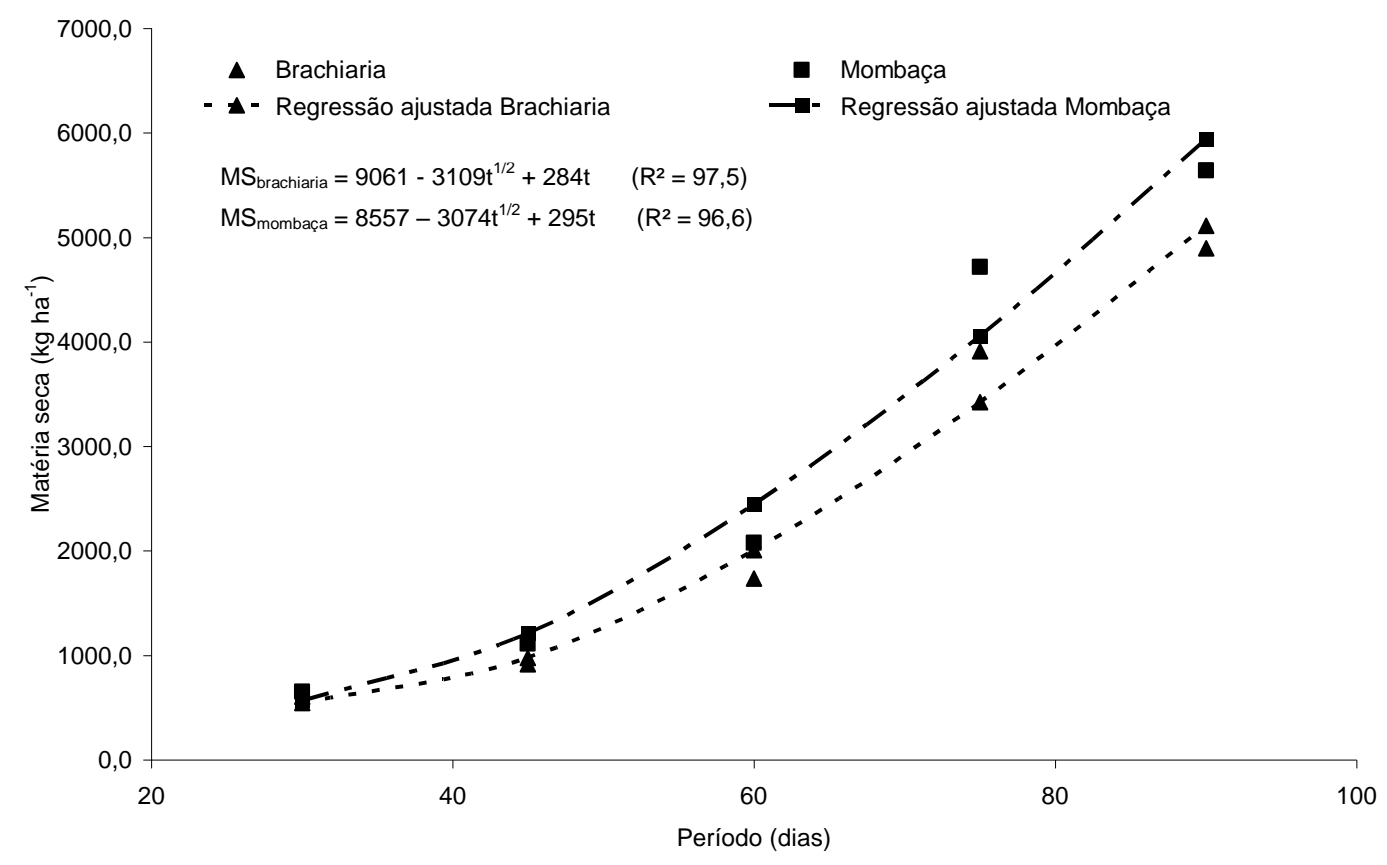

(a)

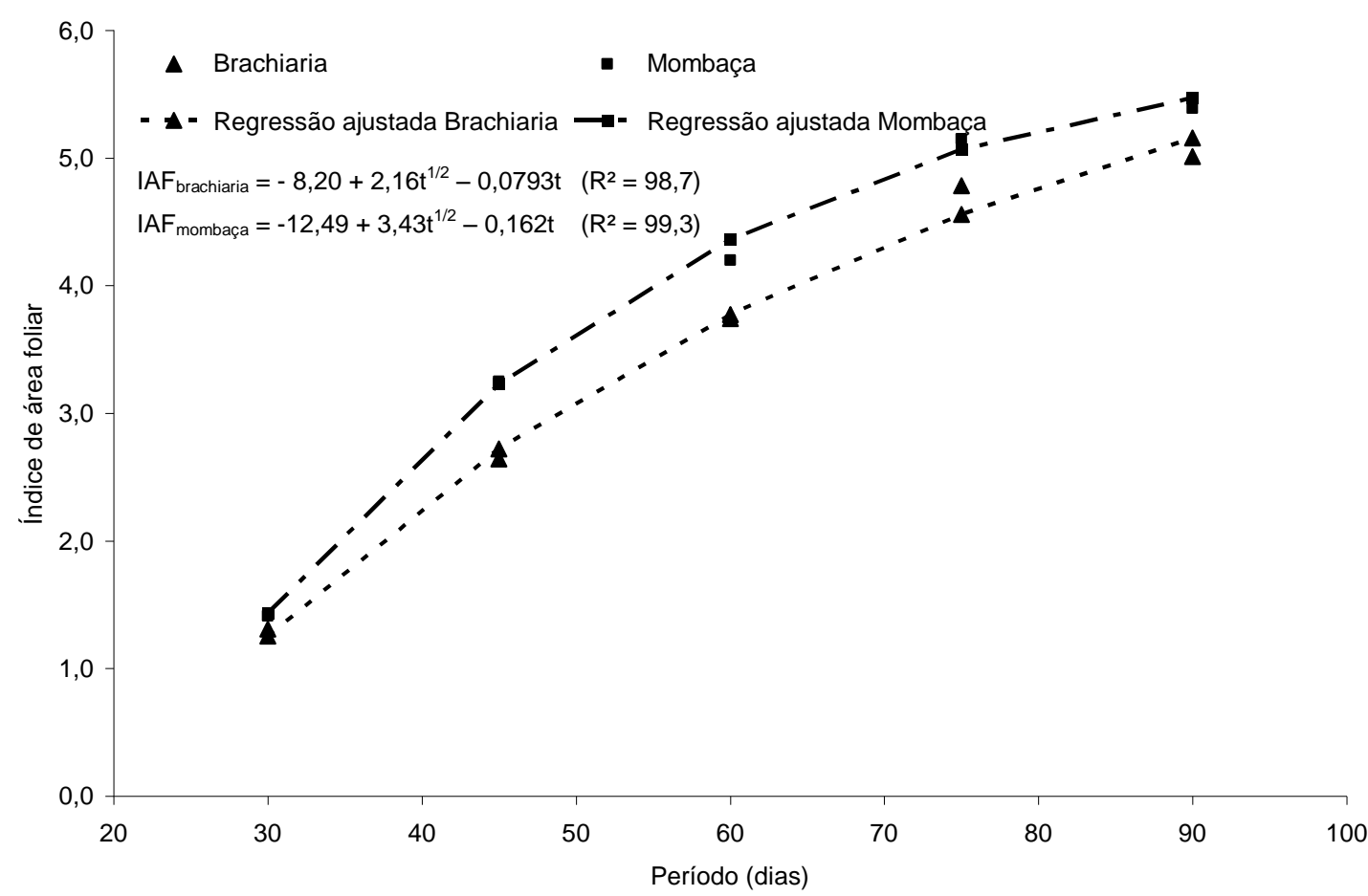

(b)

FIGURA 1. Produção de matéria seca (a) e índice de área foliar (b) para a capim-brachiaria e capim- -mombaça em função do período (dias) após a semeadura. Dry matter production (a) and LAI (b) area for grass Brachiaria and Mombaça grass a function of time (days) after sowing. 
A maior produção do capim-brachiaria em relação ao capim-mombaça é devida à eficiência de absorção de nutrientes no estágio inicial de desenvolvimento do primeiro, independentemente do manejo de solo utilizado. BARDUCCI et al. (2009) concluíram que não há resposta do capim-mombaça à adubação nitrogenada em cobertura, enquanto o capim-brachiaria aumenta a produtividade de massa seca em função do aumento da disponibilidade de nitrogênio em sistema de plantio direto.

\section{CONCLUSÕES}

Os sistemas de manejo do solo utilizados influenciaram na produção de matéria seca, independentemente da forrageira, sendo que o preparo convencional apresentou melhores resultados.

O manejo do solo não pode ser considerado isoladamente como fator relevante na produção de matéria seca e no índice de massa foliar.

O preparo convencional proporcionou maiores produções de biomassa e de índice de área foliar quando comparado ao cultivo mínimo e ao plantio direto.

\section{AGRADECIMENTOS}

À FAPEMIG - Fundação de Apoio à Pesquisa de Minas Gerais, à CAPES - Coordenação de Aperfeiçoamento de Pessoal de Nível Superior, pelo suporte financeiro.

\section{REFERÊNCIAS}

ANDRIGUETTI, M. H. Distribuição de potássio e de raízes no solo e crescimento de milho em sistemas de manejo do solo e da adubação em longo prazo. Revista Brasileira de Ciência do Solo, Viçosa MG, v. 33, n. 5, p. 1291-1301, 2009.

BARDUCCI, R. S.; COSTA, C.; CRUSCIOL, C. A.C; BORGHI, E; PUTAROV, T. C.; SARTI, L. M. N. Produção de braquiária brizantha e panicum Maximo com milho e adubação nitrogenada. Archivos de Zootecnia, Córdoba, v. 58, p. 211-222, 2009.

CASTRO, O. D.; VIEIRA, S. R.; SIQUEIRA, G. M.; Andrade, C. D. Atributos físicos e químicos de um Latossolo Vermelho eutroférrico sob diferentes sistemas de preparo. Bragantia, Campinas, v. 68, n.4, 1047-1057, 2009.

COLET, M. J.; SVERZUT, C. B.; WEIRICH NETO, P. H.; SOUZA, Z. M. D. Alteração em atributos físicos de um solo sob pastagem após escarificação. Ciência e Agrotecnologia, Lavras, v. 33, n.2, 361-368, 2009.

COSTA, A. D.; ALBUQUERQUE, J. A.; MAFRA, Á. L.; SILVA, F. R. D. Propriedades físicas do solo em sistemas de manejo na integração agricultura-pecuária. Revista Brasileira de Ciência do Solo, Viçosa MG, v. 33, n.2, 235-244, 2009.

CORTEZ, J. W.; ALVES, A. D.; MOURA, M. R. D.; OLSZEVSKI, N.; JESUS, H. Atributos físicos do argissolo amarelo do semiárido nordestino sob sistemas de preparo. Revista Brasileira de Ciência do Solo, Viçosa MG, v. 35, n. 4, 1207-1216, 2011.

CRUZ, S. C. S.; PEREIRA, F.; BICUDO, S. J.; Santos, J. R.; ALBUQUERQUE, A.; MACHADO, C. G.. Consórcio de milho e Brachiaria decumbens em diferentes preparos de solo. Acta Scientiarum Agronomy, Maringá, v. 31, n.4, 633-639, 2009.

EMBRAPA CNPS. Manual de métodos de análise de solo. 2. ed. Rio de Janeiro, 1997. $212 \mathrm{p}$

KAMIMURA, K. M.; ALVES, M. C.; ARF, O.; BINOTTI, F. F. D. S. Propriedades físicas de um Latossolo Vermelho sob cultivo do arroz de terras altas em diferentes manejos do solo e água. Bragantia, Campinas, v.68, n.3, 723-731, 2009. 
MILLER, D.K.. Weed control and cotton tolerance with CGA 362622. In: SOUTHERN WEED SCIENCE SOCIETY, 55., 2002, Atlanta. Proceedings... Atlanta: Hyatt Regency, 2002. p.30

PARIZ, C. M.; ANDREOTTI, M.; AZENHA, M. V.; BERGAMASCHINE, A. F.; MELLO, L. D.; LIMA, R. C.. Produtividade de grãos de milho e massa seca de braquiárias em consórcio no sistema de integração lavoura-pecuária. Ciência Rural, Santa Maria, v.41, n.5, 875-882, 2011.

SAS INSTITUTE. SAS user's guide: statistics, version 9.1. Cary, 2002.

SERAFIM, M. E.; OLIVEIRA, G. C.; OLIVEIRA, A. S.; LIMA, J. M.; GUIMARÃES, P. T. G.; COSTA, J. C. Sistema conservacionista e de manejo intensivo do solo no cultivo de cafeeiros na região do Alto São Francisco, MG: estudo de caso= Intensive coffee cultivation management in the physiographic region of the upper San Francisco River, MG: a case study. Bioscience Journal, Uberlândia v. 27, n. 6, p 964-977, 2011.

SPERA, S. T.; SANTOS, H. P. D.; FONTANELI, R. S.; TOMM, G. O. Integração lavoura e pecuária e os atributos físicos de solo manejado sob sistema plantio direto. Revista Brasileira de Ciência do Solo, Viçosa MG, v.33, n.1, p. 129-136, 2009.

VITÓRIA, E. L.; FERNANDES, H. C.; TEIXEIRA, M. M. Correlação linear e espacial entre produtividade de Capim-mombaça e atributos físicos solo em função do sistema de manejo. Revista Agrotecnologia, Anápolis, v.2, n.2, p.30-43, 2011. 